\title{
LOS REENCUENTROS DE ODISEO EN ÍTACA
}

\section{THE REUNIONS OF ODYSSEUS IN ITHACA}

\author{
Susana Reboreda Morillo*
}

\section{Resumen}

El mito de Odiseo podría ser calificado como uno de los más cercanos al ser humano, de cuantos nos legó la antigüedad griega. Humano, por cuanto Odiseo busca, lucha y sufre porque ama como el ser humano. Muy humano, por cuanto no podemos separar en este mito las peripecias de su fiel esposa Penélope; de su hijo Telémaco; de su padre Laertes; de su madre Anticlea, muerta de dolor por la ausencia de aquel; de su nodriza Euriclea; de su porquerizo Eumeo; de la maga Circe, que transforma en animales a los hombres; la ninfa Calipso, que ofrece la inmortalidad divina a Odiseo; la dulce y pura Nausícaa, junto a la cual Odiseo pudo haber tenido un apacible nuevo hogar en el país de los hombres felices, los feacios. Todos ellos son personajes de honda humanidad, incluido, si así podría decirse, de Argos, aquel animalito que esperó veinte años para alcanzar a ver a su dueño de regreso y darle una postrera muestra de amor y de bien morir: Disfrazado Odiseo, cuando Argos

* Profesora Titular de Historia Antigua de la Universidad de Vigo-España. lo reconoce, coleando dejó que la muerte lo atrapara, entonces Ulises desvió su mirada y enjugóse una lágrima. Aquella lágrima que les fuera negada a los dioses del olimpo solo le fue concedido a su viejo perro Argos.

\section{Abstract}

The myth of Odysseus could be described as one of the closest to the human being, of all that bequeathed us the Greek antiquity. Human, because Odysseus seeks, struggles and suffers because he loves like the human being. It is very human, because we can not separate in this myth the vicissitudes of his faithful wife Penelope; of his son Telemachus; of his father Laertes; of his mother Anticlea, dead of pain by the absence of that one; of his nurse Euriclea; of his swineherd Eumeo; of the magician Circe, who transforms men into animals; the nymph Calypso, who offers divine immortality to Odysseus; the sweet and pure Nausicaa, next to which Odysseus could have had a peaceful new home in the country of happy men, the Phaeacians. All of them are characters of deep humanity, including if you could say Argos, that little animal that waited twenty years to reach to see its owner back and give him a 
last show of love and good death: Disguised Odysseus, when Argos recognizes him he let his death take it away, then turned his gaze away and wiped away a tear. That tear that was denied them to the gods of Olympus was only granted to their old dog Argos.

\section{Palabras claves}

Amor - Homero - Mito - Ítaca - Razón Astucia - Belleza - Guerra - Valores morales

\section{Keyword}

Love - Homer - Myth - Ithaca - Reason Wits - Beauty - War - Moral values

\section{Aspectos introductorios}

\section{El amor en Grecia.}

Resulta curioso que si bien el tema del amor en Grecia ha sido ampliamente tratado desde distintas perspectivas y referido a diferentes épocas, los investigadores omiten o pasan de puntillas sobre este sentimiento en la épica homérica. Esta situación se debe, en parte, a que se entiende que surge por primera vez de forma diáfana en un momento inmediatamente posterior, a través de la poesía lírica, en la que poetas y poetisas, como Safo de Mitilene, inauguraron una poesía basada en la expresión de un sentimiento que, como veremos, en Grecia no aparecía conceptualizado como tal, al menos en la forma en que entendemos las relaciones amorosas en la actualidad, que son herencia más directa del amor cortés medieval y de la tradición romántica.

De hecho, en la Grecia Antigua no existía ninguna palabra que se pudiera traducir de forma literal por el vocablo latino amor. Muy relacionados con el amor existían los vocablos eros, ágape y philia; el primero, hacía referencia al deseo o a la atracción erótica; el segundo, definía el cariño y la caridad, y el tercero, las relaciones de amistad. Veremos como se manifiestan cada uno de estos sentimientos en la Odisea.

Una segunda dificultad que se manifiesta a la hora de trabajar sobre el tema elegido para esta charla es que forma muy especial, las investigaciones dedicadas al amor en Grecia se refieren a las relaciones homosexuales, especialmente a las masculinas, que también son las más documentadas. En la Grecia Antigua, la homosexualidad era admitida cuando ésta se restringía al contexto de la iniciación, momento en que se establecía una relación entre el joven y su tutor, probablemente de una forma más ritual que propiamente de enamorados, $o$ al menos eso es lo que transmiten las fuentes. Perpetuar esta relación más allá del período iniciático ya no estaba admitido socialmente; el motivo principal era la imposibilidad de la reproducción.

Si bien es cierto que muchos autores interpretan que entre Aquiles y su amigo Patroclo existía una relación homosexual, en ningún momento de los poemas homéricos este tipo de relaciones se hacen explícitas. El filólogo Rodríguez Adrados va más lejos cuando opina que "Homero desconoce el amor homosexual", justificando este hecho con la menor distancia social y el mayor afecto entre hombre y mujer que en épocas posteriores de la historia griega ${ }^{1}$.

Las relaciones entre hombre y mujer se establecían de una forma jerárquica y desigual, ya que la mujer, en general, se encontraba toda su vida bajo la tutela masculina, el kiros y su voluntad no intervenía en la elección de su marido, sino que éste era elegido por su tutor, en situaciones normales su padre $y$, en caso de ausencia, por su tío o su hermano. De este

1 El descubrimiento del amor en Grecia. Editorial Coloquio. Madrid, 1985, p. 169. 
modo pasaba directamente de la tutela del padre a la de su marido.

En ciertos aspectos, la situación de la mujer aparece con algo más de libertad en los textos homéricos. Así, por ejemplo, se afirma que aunque el padre de Odiseo, Alertes, había comprado a la sierva Euriclea por veinte bueyes, cuando todavía era núbil, la honró como a una esposa y nunca se unió a ella por miedo a la ira de su mujer, Anticlea. En otra ocasión, se menciona que Penélope, ante la prolongada ausencia de Odiseo, debería regresar a la casa paterna y escoger con su padre un esposo que agradase a ambos. También resulta significativo el papel igualitario que Arete, la reina de Feacia, desempeñaba junto a su marido, el rey Alcínoo.

\section{El marco de la Odisea}

\section{- Homero}

Antes de referirme de forma específica a la Odisea, me gustaría hacer unas breves referencias a Homero que ayudarán a acercarnos al interés de este autor como fuente histórica. Aunque todavía muchos aspectos de la llamada "cuestión homérica" permanecen sin solución, en la actualidad existe cierta unanimidad sobre el hecho de que los poemas son una recopilación escrita que recogen una poesía que se transmitía oralmente desde el inicio y durante toda la edad oscura (1200750). La redacción por escrito de los poemas tuvo lugar a mediados del s. VIII a.C. y en ella se narran una serie de hazañas épicas que recogen tradiciones tanto del añorado esplendor de la época micénica, como de la edad oscura, como del momento de su puesta en escrito, es decir del periodo arcaico. En cualquier caso, los datos más abundantes enlazan con su creación y transmisión oral y aunque no podamos ver en ellos un fiel reflejo de la historia, sí es factible obtener informa- ción sobre la mentalidad y ciertos usos sociales que permiten acercarnos a esos siglos oscuros; así bautizados, en parte, por la desaparición de una escritura que en el mundo micénico se empleaba básicamente al servicio del estado centralizado.

Pienso, como Finley lo hizo ${ }^{2}$, que de los poemas homéricos, en general, y de La Odisea, en particular, se puede esbozar una época de pequeños reinos, a cuya cabeza se encontraba el noble que se erigía como más poderoso de entre todos los nobles, el basileus, cuyo cargo no era hereditario. Una de las actividades principales de la nobleza era la guerra, tanto defensiva como ofensiva; de esta última dependía en gran parte su riqueza, que aumentaba con los botines apresados y que eran repartidos jerárquicamente por el basileus, en función de la categoría social del guerrero. La Ilíada refleja la unión de varios reinos griegos en una expedición contra la ciudad asiática de Troya.

La unidad socioeconómica de la Edad Oscura griega era el oikos, que incluía no solo las pertenencias materiales del noble -la casa, las construcciones anexas y la tierra-, sino también el grupo de personas que se integraban en el mismo, la familia, los sirvientes y los esclavos. El ideal de cada oikos era la autosuficiencia, por ello se intentaba, en un riguroso reparto de tareas, producir en su seno la mayoría de los productos consumidos.

La familia se consideraba como la unidad básica de la sociedad. El matrimonio era monógamo, aunque al hombre se le permitía mantener relaciones fuera del matrimonio; las concubinas, en la mayoría de los casos, eran prisioneras de guerra que se asignaban a los vencidos como una pieza más del botín. En la

Finley, M.I. El mundo de Odiseo. F.C.E. México, Madrid, Buenos Aires, 1961. 
Ilíada la cólera de Aquiles contra Agamenón es provocada porque éste arrebata al primero a Briseida, mujer que le había sido concedida en las circunstancias mencionadas.

\section{El relato de la Odisea}

Una de las cuestiones homéricas sin resolver es si ambos poemas épicos fueron redactados por un único autor, aunque existe unanimidad en que la Odisea fue escrita con posteridad a la Ilíada y no sólo por el orden de los acontecimientos que se narran, sino porque en aquélla se plantea un ideal heroico que ha evolucionado; en cierto modo, el perfil del héroe se humaniza y probablemente expresen de una forma más clara los ideales de la época.

Transcurridos los diez años de la Guerra de Troya, la Odisea relata el nostos de Odiseo, un regreso se prolongó otros diez años y que parecía que nunca iba a completarse. La principal causa de este retraso era la furia que el héroe provocó en Posidón al cegar a su hijo, el cíclope Polifemo, y, además, vanagloriarse de ello. La venganza del dios no fue la muerte, pero sí el deseo insatisfecho, el deseo de regresar a su patria y encontrarse con los suyos para envejecer en paz, como basileus de su pequeño reino de Ítaca.

En el transcurso de estos años, Odiseo, primero en compañía de sus hombres, y luego en solitario, recorrió tierras desconocidas y se encontró con gentes inhóspitas, que desconocían las normas cívicas y que, en muchos casos, ni respetaban a los temidos dioses. La única excepción fue la tierra de Esceria, que, a muchos niveles, sirve de transición al mundo conocido, ya que sus habitantes, los feacios, además de respetar las normas éticas y religiosas, trasladarán al héroe a su añorada patria.

\section{El Reencuentro}

He abordado el estudio de los poemas homéricos, en general, y de La Odisea, en particular, desde diversas perspectivas. Esta es la primera vez que lo hago en relación al amor y creo que no exagero si afirmo que esta obra está cargada de sentimientos y emociones, ingredientes imprescindibles en el amor, ese amor que hoy en día entendemos y aunque en Grecia quizás no estuviese conceptualizado, ni las relaciones amorosas se establecían con nuestras normas, sí existía como sentimiento.

Para demostrar esta afirmación he seleccionado un tema recurrente, el del reencuentro, que se manifiesta a través de toda la obra. En la primera parte, cuando Odiseo se halla lejos de su patria y de los suyos, en forma de añoranza, quizás morriña o saudade serían las palabras más idóneas para definir el estado de ánimo permanente que se refleja en este héroe, no sólo en las situaciones de peligro sino también en otras que, como veremos, ofrecen una serie de ventajas sobre la vida que le aguardaría si regresara a Ítaca.

Si en la primera parte era un profundo anhelo, en la segunda, a partir del momento en que el héroe arriba a las costas de Ítaca y el añorado reencuentro con la tierra y los seres queridos se sucede; avanza hacia una nueva sensibilidad: el deseo de venganza y de la vuelta al orden preestablecido.

A través del análisis y exposición de una serie de fragmentos seleccionados, será factible demostrar la existencia del amor, a distintos niveles y con diferentes características: a su madre, Anticlea, que, sin esperarlo, encuentra su alma en el Hades, al haberle causado la muerte el sufrimiento de la prolongada ausencia de su hijo; a la tierra que le vio nacer y crecer, Ítaca; a su diosa protectora, Atenea, que tras años de ignorarle, vuelve a prestarle apoyo 
en una empresa difícil; a su hijo, Telémaco, que abandonó cuando era un niño y reencuentra siendo casi un adulto, pero sin asumir las riendas de la casa y a su esposa, Penélope, asediada por más de cien pretendientes y sumida en una desesperación que le impedía asumir los quehaceres de una ama de casa.

Tras el análisis de estos reencuentros, espero que resulte evidente que, aunque no de una forma consciente, en la Odisea está presente un sentimiento que en nuestra época identificamos sin dudarlo con el amor, ese amor que presenta y presentaba múltiples formas (físico y sexual, maternal, como amistad...) y facetas (una inclinación, un afecto, un apetito, una pasión, una aspiración...).

\section{Los reencuentros de Odiseo y sus senti- mientos: amor y emoción}

Situación previa: morriña/saudade

En el apartado anterior aludía a la morriña como una constante manifestada por Odiseo en distintos ambientes; en cualquiera de los episodios narrados, el mayor deseo manifestado por el héroe, una vez finalizada la Guerra de Troya, era regresar a su patria con los suyos para alcanzar una vejez tranquila.

Parece evidente que el autor quiso resaltar este sentimiento de desesperación ya desde el inicio de la obra. Así, al comenzar el canto I y en la primera mención del protagonista, escoge la siguiente frase comparativa:

"Y solamente Odiseo, que tan gran necesidad sentía de restituirse a su patria y ver a su consorte, hallábase detenido en hueca gruta por Calipso, la ninfa verenanda, la divina entre las deidades, que anhelaba tomarlo por esposo" (I, 11-15) ${ }^{3}$.

3 La traducción empleada para la ilustración de esta charla es la de Luis Segelá y Estalella, editada por
La primera imagen que se ofrece de Odiseo es la del único participante en la Guerra de Troya que, todavía con vida, no ha completado su nostos, es decir su regreso. El héroe está apesadumbrado y la pena que le embarga es la lejanía de su mujer - ampliable, como veremos, a la familia- y de su hogar.

Sin embargo, la situación de Odiseo, a no ser por el sentimiento descrito, podría ser paradisíaca; se encontraba la isla de Ogigia, junto a la diosa Calipso, hija del sol, que, enamorada de él, le ofrecía no sólo una vida sin penalidades, sino también la inmortalidad eterna, con la única condición de que permaneciera para siempre a su lado. Pero estas, a simple vista, ventajas, provocan la siguiente reacción en el cautivo:

"Hallóle sentado en la playa, que allí se estaba, sin que sus ojos secasen el continuo llanto, y consumía su dulce vida suspirando por el regreso, pues la ninfa ya no le era grata. Obligado a pernoctar en la profunda cueva, durmiendo con la ninfa que le quería sin que él la quisiese, pasaba el día sentado en las rocas de la ribera del mar y consumiendo su ánimo en lágrimas, suspiros y dolores, clavaba los ojos en el Ponto estéril y derramaba copioso llanto..." (V, 151-8).

La propia Calipso, que dejará partir a Odiseo sólo cuando Zeus se lo ordene, manifiesta su extrañeza por la perpetua congoja del héroe con las siguientes palabras:

“... aunque estés deseoso de ver a tu esposa, de la que padeces soledad todos los días. Yo me jacto de no serle inferior ni en el cuerpo ni en el natural, que no pueden las mortales competir con las diosas ni por su cuerpo ni por su belleza" (V, 209- 13).

Espasa-Clape Argentina S.A. 1969, tan sólo se ha sustituido el nombre de Penelopea por Penélope. 
La respuesta del astuto Odiseo es tan ilustrativa que merece la pena su lectura:

“No te enojes conmigo, venerada deidad! Conozco muy bien que la prudente Penélope te es inferior en belleza y en estatura; siendo ella mortal y tu inmortal y exenta de la vejez. Esto no obstante, deseo y anhelo continuamente irme a mi casa y ver lucir el día de mi vuelta" (V, 215-20).

En esta afirmación es evidente que ni la dignidad de la diosa, ni la tentación de una futura inmortalidad logran desestimar la idea del regreso y el reencuentro en Odiseo.

Es posible definir la pasión que Calipso siente por el héroe como relación erótica, esa que en Grecia infunde el dios Eros y que suele acontecer fuera de la relación matrimonial.

El episodio en la isla de Calipso no supone un ejemplo aislado, de hecho, mucho antes, cuando todavía parte de los compañeros de Odiseo mantenían la vida, se les ofrece la opción de cambiar un penoso regreso lleno de riesgos, por una vida sin penalidades y con el disfrute de placeres terrenales. Me refiero al episodio de la isla de Eea que, como veremos, muestra ciertas concomitancias con el caso anterior.

En un primer momento, cuando parte del grupo se acercan al palacio de Circe, ésta los acoge según las normas de hospitalidad que rigen en el mundo civilizado y les ofrece un banquete. Tras este altruismo se esconden los oscuros designios de la diosa maga, que tiene por costumbre suministrar una droga a sus invitados con el efecto inmediato de transformarles en animales, en este caso cerdos, con el agravante de que su mente humana permanecía lúcida y eran, pues, plenamente conscientes de su nueva apariencia.

Odiseo logra, con la ayuda del dios Hermes y de su astucia, burlar y reducir a Circe, quien devuelve la forma humana a sus compañeros y se enamora del héroe a quien intenta por todos los medios mantener a su lado.

Por este motivo Circe se convirtió en la mejor anfitriona, agasajando a sus invitados con baños, ropas, y banquetes de carnes sin fin $y$ vino exquisito. Durante un año logró mantener al grupo de guerreros en su palacio.

Pero, una vez más, renació ese deseo del reencuentro y éste era tan fuerte que el héroe accedería al consejo de Circe de internarse en el Hades, en el reino de los muertos vedado a los vivos, con la única misión de pedir consejo al alma del adivino Tiresias sobre cuál era el camino por el que podría regresar a su hogar. También en este caso, como sucederá con Calipso, la relación de eros, basada en la atracción física se acaba transformando en philia, cuando las diosas acceden a ayudar al héroe a regresar a su patria.

Odiseo aún rechaza otra oferta con interesantes ventajas, en su última parada antes de llegar a su casa, en la isla de Esceria. Una vez más la tentación se establece en relación a una mujer, pero en este caso, humana. Cuando el maltrecho Odiseo arribó a la costa, se encontró con Nausícaa, la hija de los reyes, que le ofreció ropas y ayuda para llegar al palacio. Sin duda la belleza de la joven impactó a Odiseo, quien la confundió con una diosa; tampoco resulta difícil comprobar el sentimiento de ella cuando exclama:

“ ¡Ojalá a tal varón pudiera llamarle mi marido, viviendo acá!; ;Ojala le pugliera quedarse con nosotros! Mas, joh esclavas!, dadle de comer $y$ de beber al forastero... Ellas la escucharon $y$ obedecieron, llevándole alimentos y bebidas" (VI, 244-7).

La acogida que los reyes Alcínoo y Areta dan al héroe, es la primera de todos sus en- 
cuentros en el extranjero, que cumple estrictamente con las normas civilizadas de la hospitalidad griega y que aleja definitivamente a Odiseo de la situación de permanente peligro. Además le ofrecieron ayuda para completar su nostos, incluso antes de conocer quién era.

Aunque Alcínoo era consciente del deseo del héroe, no se resiste a hacerle una oferta en los siguientes términos:

“¡jalá, por el padre Zeus, Atenea y Apolo, que siendo cual eres y pensando como yo pienso, tomases a mi hija por mujer y fueras llamado yerno mío, permaneciendo con nosotros! Diérate casa y riquezas, si de buen grado te quedaras, que contra tu voluntad ningún feacio te ha de detener, pues eso disgustaría al padre Zeus. Y desde ahora decido, para que lo sepas bien, que tu viaje se haga mañana" (VII, 311-5).

La respuesta de Odiseo sólo se refiere a la segunda opción, reiterando con vehemencia el deseo de ver cumplido su regreso.

Las palabras que se dirigen Nausícaa y el héroe a modo de despedida indican, al igual que sucedía en el primer encuentro, un sentimiento que asume las características del ágape, esa relación de cariño y caridad, próxima al amor, que mencionaba en la introducción:

"Salve, huésped, para que en alguna ocasión cuando estés de vuelta en tu patria, te acuerdes de mí, que me debes antes que a nadie el rescate de tu vida. Respondióle el ingenioso Odiseo: ¡Nausícaa, hija del magnánimo Alcínoo! Concédame Zeus, el tonante esposo de Hera, que llegue a mi casa y vea el día de mi regreso, que allí te invocaré todos los días como a una diosa, porque fuiste tú, ¡oh doncella!, quien me salvó la vida" (VIII, 461).

Las tres escenas descritas con Calypso, Circe y Nausícaa ilustran de una forma diáfa- na la afirmación que comentaba al principio: el mayor anhelo del héroe, por encima de todas las cosas, era el regreso a Ítaca y el reencuentro con sus allegados.

Analicemos esos reencuentros para descubrir los distintos niveles de manifestación de ese amplio sentimiento que es el amor.

\section{Los reencuentros:}

El reencuentro con su madre, Anticlea.

El ya mencionado descenso al Hades, supone una dura prueba para Odiseo, y es en ese tétrico lugar donde tiene su primer encuentro fatal con su primer ser querido, de quien, además, desconocía su muerte. Se trata de su madre, Anticlea, a quien declara que todavía no ha regresado a su patria de la forma siguiente: “...ni entré en mi tierra, pues voy siempre errante y padeciendo desgracias desde el punto que seguí al divino Agamenón hasta Ilión, la de hermosos corceles, para combatir contra los troyanos...", (XI, 168-9).

Una vez más el héroe denuncia ese dolor, ya casi familiar, que la situación de lejanía le inflinge.

A través de la conversación que mantiene con el alma de su madre, Odiseo obtiene la oportunidad de recibir las primeras noticias directas sobre Ítaca; de este modo tras preguntarle la causa de su fallecimiento, el héroe muestra su avidez por conocer la situación de los suyos en su patria en los términos siguientes:

"Háblame de mi padre y del hijo que dejé, y cuéntame si mi dignidad real la conservan ellos o la tiene algún otro varón, porque se figuran que ya no he de volver. Revélame también la voluntad y el pensamiento de mi legítima esposa: si vive con mi hijo y todo lo guarda y mantiene en pie, o ya se casó con el mejor de los aqueos (XI, 173-179). 
La respuesta de su madre inflamará todavía más el anhelo del regreso:

"Aquella continúa en tu palacio, con el ánimo afligido, y pasa los días y las noches tristemente, llorando sin cesar, nadie posee aún tu hermosa autoridad real: Telémaco cultiva en paz tus heredades y asiste a decorosos banquetes, como debe hacerlo el varón que administra justicia, pues todos le convidan. Tu padre se queda en el campo, sin bajar a la ciudad..., sino que en el invierno duerme entre los esclavos de la casa, en la ceniza, junto al hogar, ...yace afligido y acrecienta sus penas anhelando tu regreso, además de sufrir las molestias de la senectud a que ha llegado. Así morí yo también, cumpliendo mi destino... ni me acometió enfermedad alguna... antes bien, la soledad que de ti sentía y la memoria de los cuidados y de tu ternura, preclaro, Odiseo, me privaron de la dulce vida" (XI, 181-203).

A través de esta conmovedora respuesta, Odiseo recibe las primeras noticias de sus seres queridos y la confirmación de la correspondencia de sus sentimientos; al mismo nivel, él y los suyos, desean por encima de todo que llegue el momento del reencuentro.

Un visible sentimiento de amor filial desencadena la estéril reacción de Odiseo que no hace más que incrementar su dolor: por tres veces intenta, fallidamente, abrazar el alma de su madre, que ya no es más que una sombra.

\section{El reencuentro con la diosa Atenea}

Todos y cada uno de los héroes épicos gozaban de la protección de una divinidad; el motivo de esta tutela no es uniforme: lazos familiares, religiosos o simple afinidad de caracteres. Este último caso es el que une a Atenea y a Odiseo, la primera definida como la más astuta de las dioses y el segundo como el más astuto entre los hombres. Estas son las palabras que la diosa dirige a su protegido:

“...porque ambos somos peritos en astucias, pues si tú sobresales mucho entre los hombres por tu consejo y tus palabras, yo soy celebrada entre todas las deidades por mi prudencia y mis astucias" (XIII, 296-9).

A pesar de esta afinidad, la relación entre la diosa y su protegido no era estable, y los poemas homéricos manifiestan la siguiente evolución:

En la Ilíada Atenea aparece protegiendo y aconsejando al héroe, no sólo durante la batalla, sino también en el momento de la victoria griega, que se consigue a partir de un plan urdido por ambos, es el famoso episodio del caballo de Troya que se narra en la Odisea. Sin embargo, desde el inicio del desventurado nostos del héroe, la diosa no acudió nunca en su ayuda, incluso cuando la vida de su protegido se mostraba en peligro.

El motivo es conocido, la diosa ha retirado su apoyo, de forma generalizada, a todos los griegos, por el sacrilegio que uno de ellos, Áyax, cometió en su templo en Troya al sacar por la fuerza a la sacerdotisa Casandra que había acudido allí en busca de refugio. En la Grecia Antigua los templos se consideraban lugares de asilo y no respetar esta norma provocaba la ira de los dioses. Quizás la debilidad que Atenea sentía por Odiseo, fue la causa de que éste no se encontrase entre los más desafortunados, muchos de sus compañeros fallecieron cuando la diosa, a modo de venganza, destruyó un número elevado de naves aqueas, incluida aquella en la que navegaba Ayax.

En el caso de Odiseo, la diosa manifiesta su enfado con su ausencia, a pesar de que el lazo que ambos mantenían resultaba inusual, tal y como Néstor comentó a Telémaco: "Nun- 
ca vi que los dioses mostraran a un hombre el afecto que a la vista de todos mostraba a tu padre Atenea..." (III, 221-222).

La mencionada situación de desamparo se mantuvo durante los diez años que duró su periplo, pero se transforma radicalmente una vez transcurrido ese tiempo. Así, el motivo por el cual Zeus ordenó a Calipso la libertad del héroe, obedeció al ruego al respecto que le hizo su hija. De hecho, desde que Odiseo zarpó de Ogigia, Atenea reasumió la tarea de velar por su protegido, aunque ello no implicase que desaparecieran sus sufrimientos; ya que la diosa no había manifestado su presencia, ignoraba la vuelta de su influencia beneficiosa.

Tras el último embate de Poseidón y el consiguiente naufragio que le hizo temer por su vida en varias ocasiones, Odiseo, arribó a las costas de Esceria; este es el momento en que Atenea retoma el contacto con su protegido que se describe con una importante dosis de ternura, reconociendo en el gesto que su ira está completamente aplacada:

"Y Atenea infundióle en los ojos dulce sueño y le cerró los párpados para que cuanto antes se librara del penoso cansancio (V, 491-3).

Ya se hizo referencia a que Odiseo desconocía que la diosa le facilitaba y planificaba su ansiado regreso y posterior venganza; sólo en el momento en que Odiseo, trasladado por los feacios, llega a Ítaca, la diosa accede a manifestar su presencia. Dada la personalidad de ambos, no resulta extraño que el reencuentro se convirtiese en una especie de competición desigual, en la que el ingrediente fundamental era la astucia de ambos; con ventaja para la diosa, quien, a diferencia de Odiseo, dominaba la situación y sabía quién era su adversario. Las desventajas del héroe son evidentes: en primer lugar, porque la diosa volvió irreconocible el entorno a los ojos de Odiseo, quien pensaba que los feacios lo habían abandonado en otro lugar distinto a su tierra, y en segundo, porque se le presentó con la figura de un joven pastor ovejero. El desconcierto del héroe creció cuando le informaron que se encontraba ya en Ítaca; como respuesta inventa una convincente historia sobre su pasado, tan convincente que provoca la admiración de la diosa, quien decide que cesen los engaños por ambas partes, y se manifiesta "bajo la forma de mujer alta y hermosa" que le pregunta:

“... ¿No reconoces ya a Palas Atenea, nacida de Zeus, que siempre a tu lado en tus muchos trabajos te asisto y te protejo y ha poco el afecto te atraje de aquellos feacios?" (XIII, 299-302).

Ante la realidad del reencuentro, enseguida se manifiesta un alto grado de confianza y proximidad, de hecho Odiseo le responde reprochándole que si bien estaba a su lado durante la contienda en Troya, una vez abandonada la costa, "nunca más volví a verte". El fin de los reproches se determina con el trabajo físico, que ambos realizan "codo a codo" al esconder los regalos que le entregaron en Esceria en el fondo de una cueva; después, como dos colegas, se sientan al pie del olivo sagrado para trazar un plan que elimine a los pretendientes.

De esta forma, de labios de la diosa, Odiseo obtiene la segunda información sobre los acontecimientos en Ítaca, en general, y en su propio oikos, en particular; la situación es más catastrófica de lo que su madre le había descrito: Su mujer se sentía asediada por numerosos pretendientes que, además, minaban su hacienda con banquetes continuos. Al deseo del reencuentro se le suma a partir de este momento el de venganza y el de recuperar el orden preestablecido antes de su partida a Troya. También Atenea ansía la venganza y ambos manifiestan su odio a los galanes y su deseo de acabar con ellos; ese es otro sentimiento que les une en la empresa. 
La relación de Atenea y Odiseo, una vez recuperados los cauces habituales, se puede definir como de philia, amistad; una camaradería que no suponía una relación entre iguales, ya que el héroe sabía por experiencia que podría resquebrajarse en cualquier momento. En este reencuentro resultan notables dos aspectos: el reconocimiento que ambos hacen de sí mismos en el otro por su afinidad de caracteres y el cariño que entre ambos se manifiesta y que se refleja en la alegría de poder llevar a cabo, una vez más, tareas en común. La afirmación de la diosa resulta ilustrativa:

"Siempre tú con la misma cautela en el alma: por ello no te puedo dejar entregado a tus males, que eres avispado de mente y cumplido en palabra y en prudencia" (XIII, 330-3).

Una vez reasumida esta función tutelar, la actividad de Atenea es intensa y se establece en diversos planos: con Telémaco, con Penélope y con los propios pretendientes.

\section{- $\quad$ El reencuentro con su tierra, Ítaca}

Odiseo desempeñaba el puesto de basileus de un pequeño reino que abarcaba el territorio de la isla de Ítaca, lugar en el que nació y pasó su juventud. Allí tenía importantes posesiones que constituían la principal riqueza de su oikos y albergaba en el tesoro de su casa abundantes objetos que constituían otro símbolo de su prestigio. Como muchos otros reyes de distintos estados griegos, abandonó su tierra para acudir en ayuda de Agamenón y luchar en Troya. En Ítaca la situación se fue deteriorando progresivamente a partir de que los habitantes perdieron la esperanza del regreso del monarca y los nobles que le acompañaron, así por ejemplo se denuncia que ya desde su partida no se había convocado la Asamblea (II, 26), organismo que reunía a los nobles del territorio para la toma de decisiones importantes. Además desde hacía tres años un grupo muy nu- trido de nobles presionaban para que la mujer de Odiseo eligiera a uno de ellos como esposo, y de este modo tener más posibilidades para asumir el puesto vacante de basileus. Ante la indecisión de Penélope, los pretendientes aumentaron la presión, convirtiendo su vida en un continuo banquetear a costa de la hacienda de un marido que creían muerto.

A esta situación de caos, se le añade el hecho de que en su propio palacio nadie desempeñaba el papel que la vida, al menos en teoría, le había asignado; era como si su prolongada ausencia hubiera provocado una pérdida de referencia generalizada que desubicaba no sólo a su oikos, sino también a los nobles más jóvenes de la isla.

Ya comenté que en un principio la diosa volvió irreconocible para Odiseo su tierra al envolverlo en una densa niebla. Tras la conversación mencionada en el apartado anterior, Odiseo manifestaba su incredulidad ante la idea de encontrarse en Ítaca y Atenea, disipando la nube que le transformaba el entorno, le señaló algunos lugares conocidos y de indiscutible referencia, que Odiseo, después de veinte años, saluda de este entrañable modo: "Inundado de gozo besaba la gleba nutricia y a las ninfas después invocó levantando las manos: Ninfas náyades, hijas de Zeus, yo ya bien creía que no os iba a ver más: recibid nuevamente el saludo de mi grata oración y os traeré, como en tiempos, ofrendas si propicia me deja vivir la nacida de Zeus, la rapaz Atenea, y a un tiempo prospera a mi hijo" (XIII, 354-60).

No existe ninguna duda, una parte significativa de sus anhelos se había constituido: su nostos se había completado y de nuevo se encontraba en su querida y añorada tierra.

La alegría de arribar a su tierra se vio truncada con las noticias sobre la situación de su hogar. Su prudencia le obligaba a no ser impul- 
sivo, pues debía posponer la llegada a su hogar, a la espera de cumplir el plan trazado con Atenea, quien como primera medida, para evitar que fuese reconocido, le transformó en un mendigo. Este disfraz le permitiría estudiar de cerca el terreno y averiguar quien le había sido fiel en su ausencia y quien le había traicionado. Sólo de forma muy paulatina y taimada irá revelando su personalidad. Antes que a nadie a su hijo Telémaco, momento que comentaré a continuación.

\section{- $\quad$ El reencuentro con su hijo Telémaco.}

Una vez que Atenea logró conmover a su padre para que intercediese a favor de Odiseo en la isla de Ogigia, la diosa asumió la función de preparar la victoria sobre los pretendientes y para ello, de forma paralela a la estancia del héroe en Esceria, preparó el terreno en Ítaca. En primer lugar, busca el contacto con Telémaco.

Telémaco apenas conocía personalmente a su padre, ya que cuando partió a Troya, apenas tendría un año; a pesar de esta circunstancia le idolatraba, conocía sus hazañas y anhelaba su regreso; a él se refería como "un padre glorioso, Odiseo, el divino; aquel gran sufrido, del que cuentan que antaño... arrasó la ciudad de los Teucros.

La primera mención de Telémaco en la Odisea pone de manifiesto sus sentimientos:

“...se hallaba en medio de los pretendientes con el corazón apesadumbrado, y tenía el pensamiento fijo en su valeroso padre, por si volviendo, dispersaba a aquellos por la casa y recuperaba la dignidad real y el dominio de sus riquezas" (I, 113-117).

Podríamos citar muchos fragmentos en los que Telémaco se emocionaba pensando en su añorado padre, igualándose en ambos tanto el deseo del reencuentro, como el sentimiento de venganza. Se trata de una situación muy parecida a la que veíamos con la diosa, pero en este caso la camaradería se ve sustituida por el amor paterno-filial, el sentimiento amoroso más fuerte que transmiten los poemas homéricos, el mismo que se reflejaba entre Anticlea y su hijo en el terrible Hades.

La situación de Telémaco resultaba embarazosa, ya que a pesar de que contaría con la edad suficiente para tomar las riendas de la casa, todavía no poseía la madurez necesaria para asumir esa tarea, probablemente por la falta de referencia paterna. Esta circunstancia le convertía en "espectador sufriente" de los acontecimientos que transcurrían en su casa; así sufre la presencia de los pretendientes y su insolencia al minar los bienes de su padre que él debería heredar; muchas veces aflora en él la necesidad de "hacer algo", pero esta decisión no será una realidad hasta que Atenea se acerque a él con la figura del jefe de los tafios, Mentes, y le insta a convocar, por primera vez en veinte años, la Asamblea de Îtaca; además, le aconsejó partir a Pilos y a Esparta para preguntarles, respectivamente, a Néstor y a Agamenón noticias sobre su padre. Finalmente le aconseja que después del viaje regrese a Itaca y trace un plan para acabar con los pretendientes. Las palabras de la diosa tuvieron el efecto inmediato de un cambio en la actitud de Telémaco, al sentirse más fuerte y con un valor renovado; su partida en forma de ave le manifestó tanto su categoría divina, como su apoyo.

Atenea permanecerá velando y guiando a Telémaco hasta que padre e hijo se reencuentren; de hecho, es como si el afecto fuera una continuidad del que sentía hacia Odiseo, y así lo afirma, disfrazado de Mentor: “...soy tan amigo tuyo como de tu padre, que aparejaré una velera nave y me iré contigo" (II, 286287). 
El cambio en el joven resulta tan notable que tanto su madre como los galanes se percataron enseguida; estos últimos, temerosos de esta nueva fuerza, tramaron una emboscada con el objetivo de asesinarle.

Existe un acuerdo generalizado en la idea de que los consejos de la diosa tenían como principal objetivo el preparar a Telémaco para que definitivamente entrara en la etapa de la madurez (III, 14-20); madurez, por otra parte, que era imprescindible para colaborar con su padre en la lucha contra los pretendientes. De esta forma hay que entender el viaje realizado a Pilos y a Esparta, se trataba de concluir con éxito un rito iniciático que proporcionaría el empuje necesario para sacudirse una adolescencia ya tardía.

La llegada de Odiseo se produjo en el momento en que su hijo se encontraba fuera de Íta$\mathrm{ca}$, aunque pronto regresaría. Al primer lugar al que se dirigió Odiseo, transformado en un mendigo, fue a la casa de uno de sus siervos, Eumeo, el porquerizo, que lo acogió como huésped y en seguida le dio sobradas muestras de fidelidad a su amo. Las terceras nuevas que oye sobre su palacio proceden de este hombre, quien confirmó la descripción anterior de la diosa, mostrándose incrédulo cuando aquél le anunció la inminente llegada de su amo, y argumentando que muchos ya se habían acercado a Ítaca contando mentiras a Penélope y a su hijo.

Fue en la casa de Eumeo donde se produjo el reencuentro entre Telémaco y Odiseo. La aparición de Telémaco y el recibimiento por Eumeo, delante del disfrazado mendigo, vuelve a subrayar esa realidad de Ítaca, en dónde los acontecimientos aparecían como "descolocados" o los personajes en "otro papel"; el texto siguiente es muy elocuente:

"De la suerte que el padre amoroso abraza al hijo unigénito que le nació en la senectud, y por quien ha pasado muchas fatigas, cuando éste torna de lejanos países después de una ausencia de diez años, así el divinal porquerizo estrechaba al deiforme Telémaco y le besaba, como si el joven se hubiese librado de la muerte" (XVI, 17-21).

Tal y como se hace explícito, Eumeo estaba asumiendo el papel del padre ausente, las demostraciones de cariño prosiguieron ante un Odiseo que manifestaba un grado de atención máximo, tratando de captar cuáles eran los sentimientos y las maneras de su desconocido hijo. Éste, tras reponer fuerzas con la comida y la bebida, inquirió a Eumeo, por el extranjero presente; entre ambos conversan en su presencia y sólo intervino al final del diálogo.

Momentos después, Telémaco envió al siervo a comunicarle a su madre que ya había regresado; es en el momento en que se quedan solos, cuando Atenea aconsejó al héroe que descubriese su verdadera personalidad a Telémaco, a la vez que le devolvió su apariencia real. Ante esta transformación, Telémaco le identificó con un dios y el héroe respondió:

“¡No soy ningún dios! ¿Por qué me confundes con los Inmortales? Soy tu padre, por quien gimes y sufres tantos dolores y aguantas las violencias de los hombres. Diciendo así, besó a su hijo y dejó que las lágrimas que hasta entonces había detenido le cayeran por las mejillas en tierra" (XVI, 187-192).

Tras un primer momento de incredulidad y la convincente explicación de Odiseo sobre la intervención de la diosa en su cambio de aspecto:

"Telémaco abrazó a su buen padre, entre sollozos y lágrimas. A entreambos les vino el deseo del llanto y lloraron ruidosamente, plañeando más que las aves -águilas o buitres de corvas uñas- cuando los rústicos les quitan los hijuelos 
que aún no volaban; de semejante manera, derramaron aquellos tantas lágrimas que movían a compasión" (XVI, 214-219).

Los párrafos anteriores constituyen una buena prueba de la importancia que Homero otorgaba al amor filial, padre e hijo se identificaban el uno en el otro como una prolongación. También en los padres de Odiseo: Euriclea llegó a morir de pena y Alertes se autoexcluyó del palacio y vivía como un siervo.

Ya repuestos de la fuerte emoción que les produjo el reencuentro, unidos por el deseo de venganza, Odiseo le dio las instrucciones a Telémaco sobre cómo debería actuar cuando llegase a su hogar. Así mismo, le encargó que no trasmitiese a nadie, ni siquiera a su madre o a su abuelo, su presencia en Ítaca.

El objetivo de la diosa se había cumplido de forma satisfactoria y las intervenciones posteriores de Telémaco, con su madre y con los pretendientes, anunciaban que, definitivamente, se había cumplido su ansiada transición a la madurez y que por lo tanto estaba ya dispuesto para ayudar a su padre.

\section{- $\quad$ El reencuentro con su esposa Penélope.}

Si la situación de Telémaco podía definirse como embarazosa, la de su madre era rotundamente desesperada y así se muestra en la primera vez que se le menciona en la obra, solicitando al aedo Femio, que amenizaba el banquete de los pretendientes, que eligiese para su canto un tema diferente a las historias relacionadas con la Guerra de Troya: “...pero deja ese canto triste que constantemente me abruma el corazón en el pecho, ya que se apodera de mí un pesar grandísimo que no puedo olvidar. ¡Tal es la persona de quien padezco soledad, por acordarme siempre de aquel varón cuya fama es grande en la Hélade y en el centro de Argos!" (I, 340-445).
Son muchísimas las ocasiones en las que, no sólo ella, sino otras personas, como Anticlea, Agamenón, Telémaco, Eumeo, Euriclea y la propia diosa Atenea, confirmaban el amor que sentía por su esposo y su desesperación por la larga ausencia de veinte años. Como ya se aludió, desde hacía tres la situación había empeorado notablemente, ciento ocho pretendientes la acosaban para que dejase el palacio de Odiseo, regresase al de su padre y escogieran un marido entre ambos.

Ella que mantenía viva la imagen y la esperanza del regreso de su marido, para postergar la decisión inventó el famoso ardid, anunciando que sólo se marcharía cuando finalizase de tejer la mortaja de su suegro; para que este momento no llegase, por las noches deshilaba el trabajo realizado durante el día. El engaño se mantuvo hasta que una criada infiel lo descubrió e inmediatamente lo contó a los pretendientes; de este modo, cuando llegaba el héroe a su patria la presión se encontraba en el punto más álgido. Aún así, Penélope, mantenía de forma abierta comentarios del tono del que sigue:

"Me iré a la estancia superior para acostarme en aquel lecho que tan luctuoso es para mí y que siempre está regado de mis lágrimas desde que Odiseo se fue a Ilión con los Atridas" (XVII, 101-104).

En este estado de cosas, otra mala noticia viene a ampliar su desesperación, su hijo Telémaco ha partido a Pilos, sin avisarle, para buscar noticias sobre su padre, mientras que los pretendientes le aguardaban para tenderle una emboscada y matarle.

"Oídme, amigas; pues que el Olímpico me ha dado más pesares que a ninguna de las que conmigo nacieron y se criaron: anteriormente perdí egregio esposo, que tenía el ánimo de un león y descollaba entre los dánaos en toda clase 
de excelencias... y ahora las tempestades se habrán llevado del palacio a mi hijo querido, sin gloria y sin que ni siquiera me enterara de su partida" (IV, 722-728).

Ya vimos como sus designios no se cumplen y Telémaco, auspiciado por Atenea, eludió la emboscada y regresó a Î́taca para encontrarse con su padre en la casa de Eumeo.

Hay un hecho que llama poderosamente la atención, como es que a pesar de que las manifestaciones de Penélope y las opiniones de sus allegados y conocidos resaltan, por encima de todo, su papel como esposa fiel; Odiseo por dos veces recibe el consejo específico de que le ocultase la verdad a su esposa hasta que el problema hubiera quedado definitivamente resuelto. La primera vez, en el Hades, donde el alma de Agamenón, a pesar de alabar las virtudes de Penélope, le recomendó encarecidamente que no le hiciese partícipe de todos sus pensamientos, prevención lógica si tenemos en cuenta que él fue asesinado al regresar a su hogar, por el amante de su esposa, Clitemnestra. La segunda ocasión resulta más chocante, ya que el mismo consejo procedía de Atenea, quien le asesoró en el mismo sentido en el momento en que ambos estaban tramando la estrategia para deshacerse de los pretendientes, al transmitirle la siguiente información, cuando menos equívoca:

“... más ella, suspirando en su ánimo por tu regreso, si bien a todos le da esperanzas y a cada uno le hace promesas, enviándoles mensajes, revuelve en su espíritu muy distintos pensamientos" (XIII, 379-381). Odiseo agradeció a la diosa esta información, afirmando que, de no conocerla, se hubiera encontrado una muerte similar a la de Agamenón. En definitiva, a pesar de la fidelidad manifestada por Penélope, no resulta completamente fiable; de este modo, Odiseo prohibió a todas las personas que iban conociendo su llegada, que transmitieran a su mujer una realidad que acabaría con su prolongado sufrimiento.

Odiseo, tras el reencuentro con su hijo, pidió a Eumeo, que lo trasladase al palacio, para entre los nobles mendigar su comida y, de paso, planear sobre el terreno la ansiada venganza; una vez más la resistencia del héroe es puesta a prueba al sufrir importantes vejaciones por parte de los pretendientes que prácticamente se habían adueñado de su hacienda y de su hogar, sin importarle ofender a Zeus, divinidad que protegía a todos los huéspedes, fuera cual fuera su condición social.

Así, disfrazado de mendigo y humillado por los que pretendían la mano de su mujer y devoraban sus bienes, Odiseo tiene la primera visión de su esposa, quien, a instancias de Atenea decidió mostrarse a los pretendientes; a pesar de que la diosa le aumentó su belleza y de la afirmación que Penélope hace, cuando alaban su figura: "Mis atractivos -la hermosura y la gracia de mi cuerpo-destruyéronlos los inmortales cuando los argivos partieron para Ilión, y se fue con ellos mi esposo Odiseo. Si éste, volviendo, cuidara de mi vida, mayor y más bella sería mi gloria" (XVIII, 251-255); en ningún momento el poeta describe emoción u otro sentimiento similar en el héroe, aunque sí menciona que escuchaba sus palabras.

El primer encuentro entre esposos, en una situación que recuerda al reencuentro con la diosa, transcurre con el engaño de fondo, ya que Penélope pensaba que hablaba con un mendigo, al que trató cumpliendo con las normas de hospitalidad. La primera muestra de sensibilidad por la situación de su mujer, se produce por su llanto mientras le narraba noticias sobre su esposo y su inminente llegada: "Odiseo, aunque interiormente compadecía a su mujer, que sollozaba, tuvo los ojos tan firmes dentro de los párpados cual si fueran de cuerno 
o de hierro, y logró con astucia que no se le rezumasen las lágrimas" (XIX, 209-213).

Todo apunta a que el engaño de Odiseo se debía a su prioridad en comprobar en directo, tal y como lo hizo con los siervos de la casa, la fidelidad de su esposa; quizás por el temor a un fin similar al de Agamenón. Sólo una vez que la matanza de los pretendientes ha tenido lugar, el héroe permitió a su esposa conocer la verdad sobre su llegada. Sin embargo, en el éxito de su empresa será fundamental la intervención de Penélope, ya que fue ella quien propuso a los pretendientes la prueba del arco, aquél que venciese sería elegido como esposo; también fue ella quien descendió a la sala del tesoro y subió el arco de Odiseo a la sala, arco que, una vez en manos de su dueño, supuso la perdición y la muerte de los nobles.

En cualquier caso, una vez que la venganza se consumó con la muerte también de los sirvientes que le habían traicionado, Odiseo, permitió a Euriclea transmitir su presencia y la muerte de los pretendientes a Penélope, quien dormía a instancias de Atenea:

“Despierta. Penélope, hija querida, para ver con tus ojos lo que ansiabas ver todos los días. Ya llegó Odiseo, ya volvió a su casa, aunque tarde, y ha dado muerte a los ilustres pretendientes que contristaban el palacio, se comían los bienes y violentaban a su hijo" (XXIII, 5-9).

La respuesta de Penélope fue de una justa incredulidad, atribuyendo a un dios la matanza perpetrada; así aunque ya se encontraba frente a su esposo, permanecerían las dudas; incluso su hijo le increpó por su frialdad, pues lo único que alcanzaba a hacer era mantenerse a cierta distancia y observar en silencio. En ese momento los papeles se invertían y era la esposa quien deseaba probar a su supuesto marido; es decir, comprobar que no era un impostor: "Pero si verdaderamente es Odiseo que vuelve a su casa, ya nos reconoceremos mejor, pues hay señas para nosotros que los demás ignoran" (XXIII, 108-110).

El mutuo reconocimiento se producía, finalmente, en un contexto lleno de ternura, impulsada porque la prueba a la que le somete Penélope, se relacionaba con una trampa sobre el lecho nupcial, que Odiseo había construido con sus manos a partir del tronco de un olivo. Superada con éxito la prueba, los sentimientos afloraron por ambas partes; los párrafos siguientes muestran los sentimientos de forma diáfana:

"Penélope sintió desfallecer sus rodillas y su corazón, al reconocer las señales que Odiseo daba con tal certidumbre. Al punto corrió a su encuentro, derramando lágrimas; echóle los brazos alrededor del cuello, le besó la cabeza..." (XXIII, 205-208).

"Y Odiseo lloraba, abrazado a su dulce y honesta esposa..." (XXIII, 231-232). "Llorando los hallara la Aurora de rosáceos dedos, si Atenea, la deidad de los ojos de lechuza, no hubiese ordenado otra cosa; alargó la noche, cuando ya tocaba a su término, y detuvo en el Océano a la Aurora de áureo trono, no permitiéndole uncir los caballos de pies ligeros que traen la luz a los hombres" (XXIII, 241-245).

"Después de que los esposos hubieran disfrutado del deseable amor, entregáronse al deleite de la conversación. La divina entre las mujeres refirió cuánto había sufrido en el palacio al contemplar la multitud de funestos pretendientes... Odiseo, del linaje de Zeus, contó a su vez cuántos males había inferido a otros hombres y cuántas penas habia arrastrado en sus propios infortunios" (XIII, 300-308).

Por primera vez, en estos párrafos se nos ofrece una relación equilibrada entre ambos esposos; los engaños, las ventajas y desven- 
tajas, las desconfianzas y sobre todo el sufrimiento de la separación se habían superado. Tras la relación de ágape, afecto/caridad que Penélope estableció con el mendigo, llegó, con el reconocimiento, la pasión, es decir el eros y también la philia que identificábamos con la amistad. Todos los sentimientos que vimos repartidos en las otras relaciones extramatrimoniales del héroe con diosas y mujeres, son compartidos con su esposa; pero es preciso subrayar que la identidad de este reencuentro entre marido y mujer, aunque lleno de ternura, no alcanzaba el sentimiento profundo manifestado en el descrito entre el héroe y su hijo.
Tras este recorrido por los sentimientos en la Odisea me gustaría finalizar con un pensamiento de Platón manifestado en el Banquete quien afirma que el amor es siempre amor a algo. El amante no posee este algo que ama, porque entonces no habría ya amor. Tampoco se halla completamente desposeído de él, pues entonces ni siquiera lo amaría. El amor es el hijo de la Pobreza y de la Riqueza; es una oscilación entre el poseer y el no poseer, el tener y el no tener.
4 J. Ferrater Mora: Diccionario de Filosofía. Vol. I, Madrid, 2005, R.B.A, p. 134. 